\title{
The Outcome of Hook Plate for Lateral Third Clavicle Fractures
}

ISSN: 2576-8875

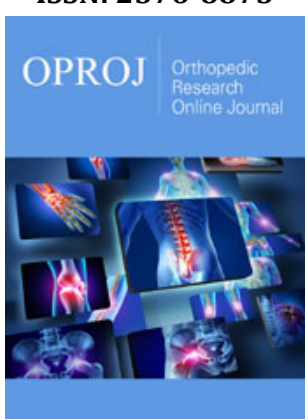

${ }^{* 1}$ Corresponding author: Ahmad I, Department of Orthopaedic and Spine surgery, Peshawar, Pakistan

Submission: 海 August 20, 2019

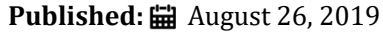

Volume 5 - Issue 5

How to cite this article: Ahmad I, Ali A, Khan Z, Kashif S, Saeed M. The Outcome of Hook Plate for Lateral Third Clavicle Fractures. Ortho Res Online J. 6(1). OPROJ.000626.2019.

DOI: 10.31031/OPROJ.2019.06.000626

Copyright@: Ahmad I, This article is distributed under the terms of the Creative Commons Attribution 4.0 International License, which permits unrestricted use and redistribution provided that the original author and source are credited.

\author{
Ahmad I*, Ali A, Khan Z, Kashif S, Saeed M, Ullah S, and Arif M
}

Department of Orthopaedic and spine surgery, Hayatabad Medical Complex, Peshawar, Pakistan

\begin{abstract}
Objectives: The objective of this study was to assess the outcome of displaced lateral third clavicle fractures which were fixed using hook plates.

Introduction: The lateral third clavicle fractures in adults are unstable fractures requiring operative treatment and are prone to non-union and delayed union. The clavicle hook plate is one of the many operating techniques that can achieve a high rate of union and relatively low rate of complications for this type of fracture, as evident from its extensive use in the last decade or so. Literature suggests good results with many studies reporting union rates of up to $100 \%$. However, the technique is not without its fair share of controversies regarding complications like shoulder impingement, resulting in long term shoulder pain and subacromial osteolysis. We aim to assess the outcome of the patients treated with hook plate and determine whether this technique has good outcome.
\end{abstract}

Methods: 22 patients, who were previously operated on at two health-care centres of Peshawar from April 2016 to March 2019 for displaced fractures of the lateral third of the clavicle by using hook plate technique, were assessed retrospectively from case records and radiographs and clinical examinations of patients, to determine their functional and radiological outcome. The follow-up duration ranged from six months to three years.

Result: The average age was 31.6 years with range of 18 to 53 years. Among these 17 were males and 5 females. All the fractures united successfully making the union rate $100 \%$. The implant was removed from 6 of the cases, with only 3 of them due to complications. One of them had a periprosthetic fracture while the other 2 experienced persistent pain and limitation of abduction. Only $37 \%$ of the patients had long-lasting pain and $16 \%$ complained of stiffness with all of them returning to their work/sports successfully. The functional outcome according to constant score was above 80 in $90 \%$ cases.

Conclusion: Surgical fixation of lateral-third clavicle fractures with a hook plate is an effective technique resulting in excellent rate of union and relatively good functional outcome.

\section{Introduction}

Clavicle fractures account for around $2.6 \%$ of all fractures and are common in young and active individuals [1]. Majority of the clavicle fractures are due to mechanisms involving highspeed falls or those that involve violent collisions. Such mechanisms cause a direct blow to the shoulder. Lateral third fractures are the second most common clavicle fractures, mid-shaft fractures being the most common [1-3]. The lateral third clavicle fractures have been classified by Neer according to the ligamentous injury and degree of displacement. Type I is the least severe injury in which the coracoclavicular ligaments are intact. In type II the coracoclavicular ligaments detach from the medial fragment with only the trapezoidal ligament remaining attached. Type III is a distal clavicular fracture that extends into the Acromioclavicular joint $[1,4]$.

While majority of the clavicle shaft fractures can be successfully treated conservatively $[1,5-7]$. The displaced lateral third clavicle fractures have a significantly high non-union rate and can result in delayed union, as they are unstable fractures. Therefore, the treatment of these lateral third fractures is often operative $[2,8]$. There are many operating techniques to fix such fractures, including trans articular k-wires, tension band, coracoclavicular screw, recontoured locking plates and dacron band fixation, with all of them providing good results. The hook plate is one such technique that has been used extensively in the past few decades with excellent outcomes, achieving a high rate of union and relatively low rate of complications $[4,9]$. Literature suggests good results with many studies reporting union rates of up to $100 \%$ 
[3,4,10-15]. However, the technique is not without its fair share of controversies regarding complications like shoulder impingement by the implant resulting in long term shoulder pain $[11,16,17]$. We aim to assess the outcome of the patients treated with hook plate and to determine whether this technique results in a successful treatment (Figure 1).

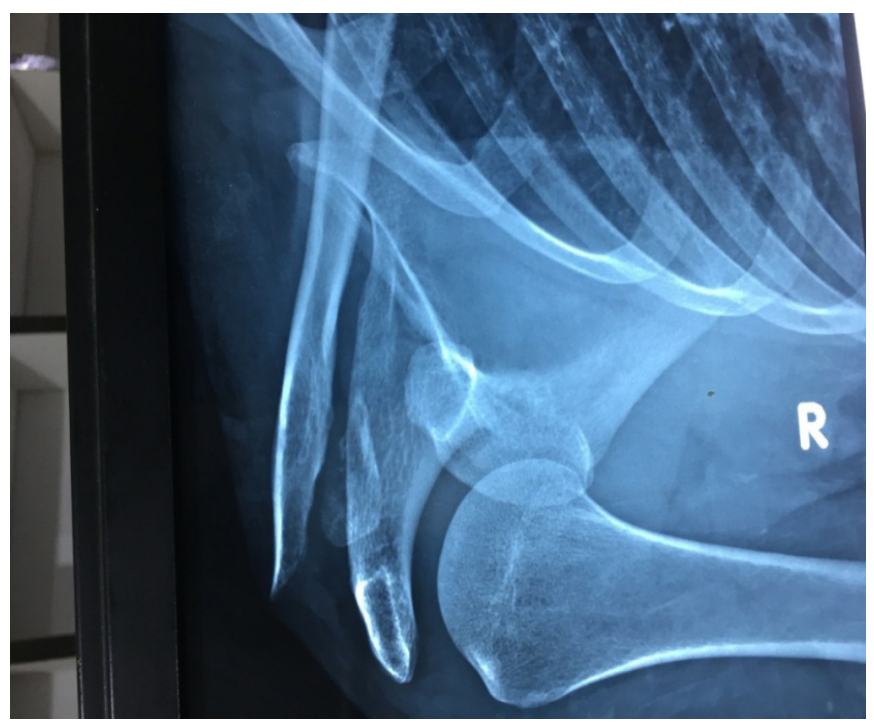

Figure 1: Displaced lateral third clavicle fracture.

\section{Methods}

A total of 22 patients were included in this study, who were treated from April 2016 to March 2019 at the Department of Orthopaedic and Spine surgery Hayatabad medical complex and Khyber Medical Centre Dabgari Garden Peshawar. After acquiring an informed consent from the patients and proper pre-operative evaluation and preparation, the patients were operated on under

\section{Result}

Table 1: Demographic data of patients. general anaesthesia. Local aesthetic and adrenaline were used in the wound site to aid in minimizing per-operative bleeding. After properly exposing and reducing the fracture, the hook plate was slid under the posterior aspect of the acromion, pressing the plate and aligning it with the clavicle on superior surface and fixed. The average time period of the procedure was around 35 minutes with about $200 \mathrm{ml}$ of blood loss. The usual post-operative routine was to keep the patient's arm in a polysling for two weeks and then start exercise gradually. The follow-up time period ranged from a minimum of 6 months to a maximum of 3 years post-operatively (Figure 2).

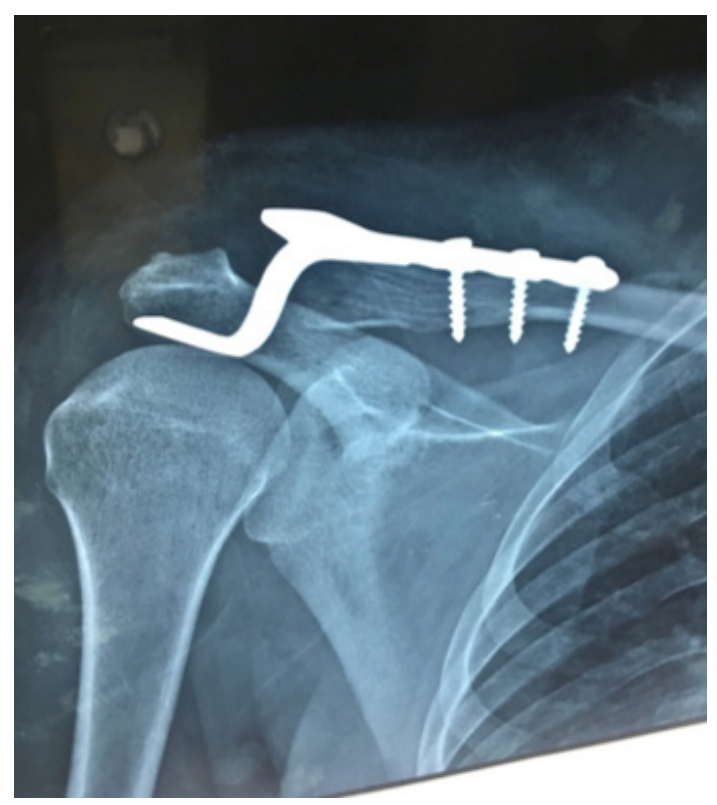

Figure 2: United lateral third fracture with hook plate.

\begin{tabular}{|c|c|c|c|c|c|c|c|c|}
\hline No & Age & Gender & Site & Duration Days & F up Months & Complaints & Result & Remarks \\
\hline 1 & 34 & M & $\mathrm{R}$ & 4 & 24 & Some pain & United & removed \\
\hline 2 & 25 & M & $\mathrm{R}$ & 6 & 24 & None & United & Playing polo \\
\hline 3 & 19 & M & $\mathrm{L}$ & 7 & 23 & Stiffness some & United & \\
\hline 4 & 31 & M & $\mathrm{R}$ & 3 & 23 & None & United & \\
\hline 5 & 40 & $\mathrm{M}$ & $\mathrm{L}$ & & & None & United & \\
\hline 6 & 53 & M & $\mathrm{R}$ & & & None & United & \\
\hline 7 & 34 & $\mathrm{~F}$ & $\mathrm{~L}$ & 12 & 23 & $\begin{array}{l}\text { Fracture medial } \\
\text { to plate with fall }\end{array}$ & $\begin{array}{l}\text { New fracture } \\
\text { treated conserva- } \\
\text { tively }\end{array}$ & $\begin{array}{l}\text { Healed and plate } \\
\text { removed }\end{array}$ \\
\hline 8 & 50 & $\mathrm{M}$ & $\mathrm{R}$ & 3 & 17 & Pain mild & United & Removed \\
\hline 9 & 34 & $\mathrm{~F}$ & $\mathrm{R}$ & 4 & 16 & Pain & United & Removed \\
\hline 10 & 23 & M & $\mathrm{R}$ & 17 & 16 & None & United & \\
\hline 11 & 22 & M & $\mathrm{L}$ & 21 & 28 & Stiffness & United & \\
\hline 12 & 25 & M & $\mathrm{L}$ & 15 & 14 & Pain and stiff & United & \\
\hline 13 & 47 & M & $\mathrm{R}$ & 3 & 12 & Stiffness & United & \\
\hline
\end{tabular}




\begin{tabular}{|c|c|c|c|c|c|c|c|c|}
\hline 14 & 38 & F & $\mathrm{R}$ & 4 & 13 & None & United & \\
\hline 15 & 24 & M & $\mathrm{R}$ & 2 & 12 & None & United & $\begin{array}{l}\text { Removed on de- } \\
\text { mand }\end{array}$ \\
\hline 16 & 27 & M & $\mathrm{L}$ & 17 & 36 & Pain & United & \\
\hline 17 & 31 & M & $\mathrm{R}$ & 3 & 11 & mild pain & United & \\
\hline 18 & 33 & $\mathrm{~F}$ & $\mathrm{R}$ & 3 & 10 & Pain & United & Removed \\
\hline 19 & 18 & $\mathrm{~F}$ & $\mathrm{~L}$ & 8 & 10 & None & United & \\
\hline 20 & 32 & M & $\mathrm{L}$ & 10 & 6 & None & United & \\
\hline 21 & 34 & M & L & 11 & 32 & None & United & \\
\hline 22 & 23 & M & $\mathrm{R}$ & 7 & 30 & None & United & \\
\hline
\end{tabular}

The average age of the patients was 31.6 years with a range of 18 years to 53 years. There were 17 males and 5 female patients with 13 of them injuring their right shoulder while the left side was involved in 9 of the cases. The commonest cause of their injuries were motor vehicle accidents and falls from height or sports injuries. All the fractures united successfully. There was no infection in any case. The implant was removed from 6 of the cases. Only 3 of the cases had their implants removed due to complications, one due to a periprosthetic fracture while the other two dues to persistent pain after successful fracture healing. The remaining three implants were removed 15 months post-operatively without any complications. No patient had subacromial osteolysis. Persistent shoulder pain and limited range of motion (especially abduction), was the most common complaint by the patients who underwent hook plate fixation. The Constant Murley scoring system showed score of 90 and above in $4(18 \%)$ cases, $80-90$ in $16(73 \%)$ cases, below 80 in two (9\%) cases (Table 1).

\section{Discussion}

Most authors agree that lateral clavicle fractures which are displaced need surgical fixation. There are many methods available including Kirchner wire fixation, locking plate fixation and lately hook plate fixation $[7,10,18,19]$. The use of the hook plate for fixation of displaced lateral third clavicle fractures in our setup yielded arguably good results with acceptable and encouraging functional outcomes. A study by Mousa [19] from Egypt showed over $90 \%$ union rate and the outcome was graded excellent in both short term and long term follow ups.

Lee et al. [20] from South Korea showed 100\% union rate but had shoulder stiffness in up to $22 \%$ of their patients with Neer Type II fractures. Overall results were satisfactory. Another study published in Pakistan journal of medical sciences also showed significantly better results in lateral third fractures treated with hook plates thank wires [21] (Figure 3).

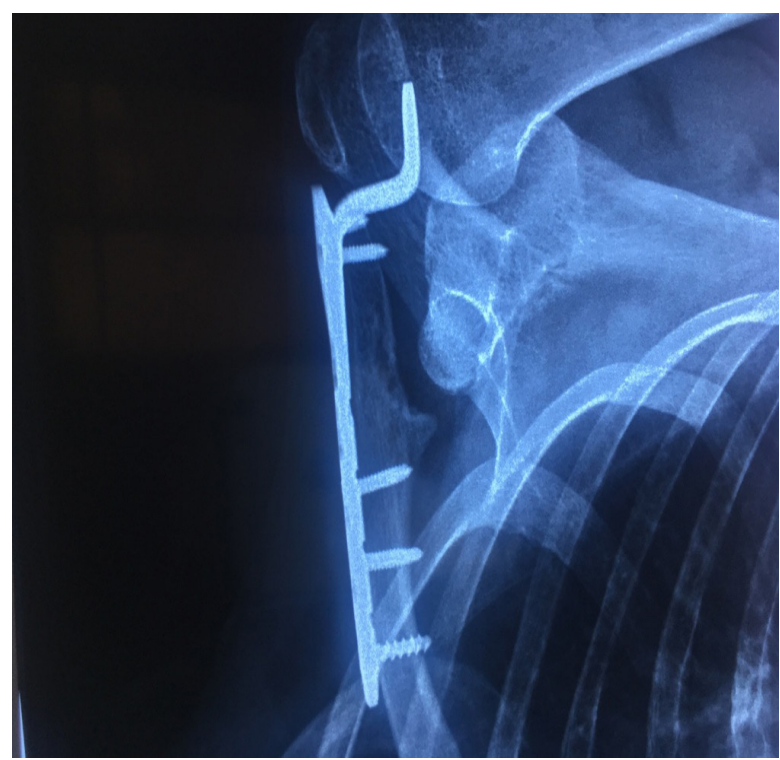

Figure 3: Healed lateral third fracture.

Although we instruct and refer our patients to the Physiotherapy department for proper and early post-operative rehabilitation, very few of them actually follow and complete the programme properly. This was probably one of the chief factors in preventing some of the patients from achieving a full range of motion at the shoulder joint. Adding substance to this argument was the fact that in those who actively followed the post-operative rehabilitation instructions, stiffness was not an issue. Two of the patients were professional 
Polo players and are currently pain free with healed fractures and are actively playing. Tiren et al. [5] showed 96\% union rate and Constant Murley score of 97 in their patients with lateral third clavicle fractures. $32 \%$ of their patients had impingement symptoms while $22 \%$ developed osteolysis in subacromial region.

A significant limitation of the hook plate technique is that the implant has to be removed once the fracture has united. This could be a deciding factor for some surgeons and or patients against this technique, although in our setup, this was not an issue as the resulting benefits greatly outweighed this. Swamy [22] from India had also excellent union rate with 87 Constant score and had infection in one case. He recommends routine removal of plate after fracture healing to prevent complications. Our results were in line with those of other such studies carried out around the world with comparable outcomes and we found the hook plate fixation to be an excellent and satisfactory method for fixing fractures of the lateral third of the clavicle. There is some disagreement about the removal of plate after fracture unites, most authors recommend removal. Otherwise there is risk of fracture medial to the plate in sportsman with falls $[5,14$, ,22-25].

\section{Conclusion}

Hook plate fixation of lateral third clavicle fracture has excellent results in terms of union and functional outcome. It has short duration of surgery and low complications.

\section{References}

1. Heckman JD, McQueen MM, Ricci WM, Tornetta P, McKee MD (2015) Rockwood and green's fractures in adults: Wolters Kluwer Health, Philadelphia, Pennsylvania, USA.

2. Charles S, Neer I (1963) Fracture of the distal clavicle with detachment of the coracoclavicular ligaments in adults. Journal of Trauma and Acute Care Surgery 3(2): 99-110.

3. Meda PV, Machani B, Sinopidis C, Braithwaite I, Brownson P, et al. (2006) Clavicular hook plate for lateral end fractures: a prospective study. Injur 37(3): 277-283.

4. Tambe AD, Motkur P, Qamar A, Drew S, Turner SM (2006) Fractures of the distal third of the clavicle treated by hook plating. Int Orthop 30(1): 7-10.

5. Tiren D, van Bemmel AJ, Swank DJ, van der Linden FM (2012) Hook plate fixation of acute displaced lateral clavicle fractures: mid-term results and a brief literature overview. J Orthop Surg Res 7: 2 .

6. Kashii M, Inui H, Yamamoto K (2006) Surgical treatment of distal clavicle fractures using the clavicular hook plate. Clin Orthop Relat Res 447: 158-164.

7. Bajuri MY, Maidin S, Rauf A, baharuddin M, Harjeel S (2011) Functional outcome of conservatively treated clavicle fractures. Clinics 66(4): 635639.

8. Rokito AS, Zuckerman JD, Shaari JM, Eisenberg DP, Cuomo F, et al. (2002) A comparison of nonoperative and operative treatment of type II distal clavicle fractures. Bulletin-Hospital for Joint Diseases 61(1-2): 32-39.
9. Flinkkila T, Ristiniemi J, Hyvonen P, Hamalainen M (2002) Surgical treatment of unstable fractures of the distal clavicle: a comparative study of Kirschner wire and clavicular hook plate fixation. Acta Orthop Scand 73(1): 50-53.

10. Haidar SG, Krishnan KM, Deshmukh SC (2006) Hook plate fixation for type II fractures of the lateral end of the clavicle. J Shoulder Elbow Surg 15(4): 419-423.

11. Renger R, Roukema G, Reurings JC, Raams P, Font J, et al. (2009) The clavicle hook plate for Neer type II lateral clavicle fractures. Journal of Orthopaedic Trauma 23(8): 570-574.

12. Muramatsu K, Shigetomi M, Matsunaga T, Murata Y, Taguchi T (2007) Use of the AO hook-plate for treatment of unstable fractures of the distal clavicle. Archives of Orthopaedic and Trauma Surgery 127(3): 191-194.

13. Lee YS, Lau MJ, Tseng YC, Chen WC, Kao HY, et al. (2009) Comparison of the efficacy of hook plate versus tension band wire in the treatment of unstable fractures of the distal clavicle. Int Orthop 33(5): 1401-1415.

14. Klein SM, Badman BL, Keating CJ, Devinney DS, Frankle MA, et al. (2010) Results of surgical treatment for unstable distal clavicular fractures. J Shoulder Elbow Surg 19(7): 1049-1055.

15. Tan HL, Zhao JK, Qian C, Shi Y, Zhou Q (2012) Clinical results of treatment using a clavicular hook plate versus a T-plate in neer type II distal clavicle fractures. Orthopedics 35(8): e1191-e1197.

16. Lee KW, Lee SK, Kim KJ, Kim YI, Kwon WC, et al. (2010) Arthroscopic-assisted locking compression plate clavicular hook fixation for unstable fractures of the lateral end of the clavicle: a prospective study. Int Orthop 34(6): 839-845.

17. Kaipel M, Majewski M, Regazzoni P (2010) Double-plate fixation in lateral clavicle fractures-a new strategy. J Trauma 69(4): 896-900.

18. Flinkkila T, Ristiniemi J, Lakovaara M, Hyvonen P, Leppilahti J (2006) Hook-plate fixation of unstable lateral clavicle fractures: a report on 63 patients. Acta Orthop 77(4): 644-649.

19. Mousa AE, Zayda AI, Ebied AM (2017) Evaluation of hook plate for fixation of displaced lateral third fractures of the clavicle. Menoufia Med J 30(2): 425-433.

20. Lee W, Choi CH, Choi YR, Lim KH, Chun YM (2017) Clavicle hook plate fixation for distal third clavicle fracture (Neer Type II): Comparison of types IIA and IIB. J Shoulder Elbow Surg 26(7): 1210-1215.

21. Dou Q Ren X (2014) Clinical therapeutic effects of AO/ASIF clavicle hook plate on distal clavicle fractures and acromioclavicular dislocations. Pak J Med Sci 30(4): 868-871.

22. Swamy A, Swamy A (2017) Treatment of displaced lateral clavicular fractures with hook plate, a retrospective study. Int J Orthop sci 3(3): 624-627.

23. Bhangal KK, Evans SC, Gibbons CE (2006) Treatment of displaced lateral clavicle fractures with the AO hook plate. European Journal of Trauma 32(5): 468-470.

24. Lu CK, Kao FC, Hsu KY, Wu CH, Yen CY, et al. (2011) Evaluation of a clavicle hook plate for fixation of unstable distal end comminuted clavicle fractures: seven case reports. Formosan Journal of Musculoskeletal Disorders 2(3): 102-105.

25. Mizue F, Shirai Y, Ito H (2000) Surgical treatment of comminuted fractures of the distal clavicle using wolter clavicular plates. J Nippon Med Sch 67(1): 32-34. 